\title{
A NECESSÁRIA REDISCUSSÃO DA CATEGORIA DIVISÃO SEXUAL DO TRABALHO: INFERÊNCIAS A PARTIR DE ANÁLISES DE EXPERIÊNCIAS TRANS*
}

\author{
Carolina Gonçalves Santos de Brito \\ Carla Cristina Lima de Almeida \\ Guilherme Silva de Almeida
}

\section{Introdução}

A divisão sexual do trabalho consiste numa modalidade da divisão social do trabalho, da mesma forma que a divisão entre o trabalho manual e o trabalho intelectual ou a divisão internacional do trabalho (KERGOAT, 1989, p. 89). Não configura, portanto, "a única forma de divisão social do trabalho: ela articula-se, interpenetra-se com outras formas de divisão social" (KERGOAT, 1989, p. 89), a exemplo dos debates em torno da divisão racial do trabalho (GONZÁLEZ, 2018).

Estudos feministas em torno da problemática da divisão sexual do trabalho desvelam relações de classe e relações de gênero, relações e práticas de trabalho e relações e práticas de gênero, enquanto indissociáveis. Deste modo, questionam e recusam análises sexualmente cegas a respeito do mundo do trabalho e reivindicam a imprescindibilidade de pensar a classe trabalhadora no feminino (a exemplo, Kergoat, 1989; Souza-Lobo, 1991; Hirata, 2002).

O conceito de divisão sexual do trabalho emergiu em torno de concepções rígidas de masculinidades e feminilidades, e, neste sentido, a diversidade trans não se constituiu objeto (direta ou indiretamente) de atenção nos estudos pioneiros acerca da divisão sexual do trabalho. Aqueles estudos, em outras palavras, não visualizaram identidades de gênero para além de expressões binárias e cisgêneras, processo relacionado à visibilidade das relações de gênero na perspectiva da época em que foram produzidos.

DOI - 10.29388/978-65-86678-15-4-0-f.49-70 
“O prefixo 'cis', de origem latina, significa 'posição aquém' ou ao 'mesmo lado', fazendo oposição ao prefixo 'trans' que significa 'posição além’ ou 'do outro lado'.” (BAGAGLI, 2015, p. 13), donde “cisgeneridade torna-se o termo adequado para indicar oposição à transexualidade/travestilidade/transgeneridade e afins" (ALMEIDA, 2018, p. 176). Falamos em pessoas trans referindo-se àquelas que, em qualquer momento da vida, desenvolvem identidades dissidentes ao gênero imposto quando do nascimento, atribuído com base na anatomia genital.

Apesar da visibilidade pública de pessoas trans constituir-se recente, experiências e vivências trans não são expressões contemporâneas. Fala-se muito pouco de pessoas trans em décadas anteriores porque "as relações sociais produzem os meios para que a existência de determinados indivíduos e grupos oprimidos não seja percebida, registrada ou celebrada [...]" (ALMEIDA, 2018, p. 159). Em outras palavras, ao pensar identidades trans - "a exemplo do que sugeriu Jurema Werneck (2013) com relação às mulheres negras cisgêneras -, frequentemente, não estamos diante da tão afirmada invisibilidade, mas de processos de invisibilização" (ALMEIDA, 2018, p. 159 - grifos no original).

Processos afetados mesmo por um maior e crescente protagonismo e lutas travadas pelas pessoas trans (ALMEIDA, 2018), cujas incidências agitam, adentram, e impulsionam o âmbito da produção sociológica, sentidas mediante alargamento e espraiamento, especialmente a partir das últimas décadas do século XX, da problemática da diversidade de gênero no campo de estudos de gênero/sexualidade nas ciências sociais.

Mediante diálogo com estudos da divisão sexual do trabalho conjugados à literatura sobre diversidade de gênero apresenta-se uma reflexão teóricoconceitual acerca das experiências laborais de pessoas trans à luz do conceito de divisão sexual do trabalho, bem como acerca dos efeitos da concepção cisheteronormativa no ordenamento do trabalho. Por outro lado, busca-se revisitar o mundo do trabalho e, em especial, o conceito e debate contemporâneo da divisão sexual do trabalho à luz destas experiências.

\section{1. "E se o trabalho tivesse muitos sexos?": ${ }^{1}$ problemati- zando experiências laborais trans}

${ }^{1}$ De acordo com Souza-Lobo (1986, orelha do livro), "a pergunta provocativa: e se o trabalho tivesse um sexo?" constitui o fio condutor das reflexões reunidas no livro "O sexo do trabalho", o qual, publicado originalmente no ano de 1984 na França, e no Brasil no ano de 1986 reúne artigos cujas contribuições direcionam-se a pensar a indissociabilidade entre relações de classe e de gênero, a divisão sexual do trabalho e o trabalho no feminino. 
O amálgama bastante variado de facetas de dificuldades quanto à inserção e permanência de trabalhadores/as trans no mundo do trabalho, bem como o retrato de condições e relações laborais comuns e particulares face aos demais segmentos da classe trabalhadora, leva-nos a refletir acerca da complexidade que o direito ao trabalho de pessoas trans assume no seio das relações sociais capitalistas-cisheteronormativas-raciais-patriarcais.

Reitera-se a reflexão em torno desta complexidade: demissões - advindas de empregadores/as ou "solicitadas" pelos/as trabalhadores/as trans após situações insustentáveis de permanência no emprego -, desistência de candidatar-se a processos seletivos, abandono dos empregos, ou mesmo a não contratação, bem como o percebimento de pagamento inferior ao combinado, o não recebimento e/ou dificuldades de promoção, bem como condições de trabalho insalubres e/ou brutais, em razão da condição trans.

A inserção no mundo do trabalho, quando lograda, acompanha-se, não raramente, de relações laborais intensamente precarizadas, haja vista o convívio no cotidiano de trabalho (que consiste, muitas vezes, na maior parte do cotidiano de vida) com sistemáticas violações de direitos relacionadas ao reconhecimento/respeito à identidade/expressão de gênero. Na tentativa de construção de novas memórias do cotidiano laboral, migrações constantes em busca de relações de trabalho menos hostis e degradantes constituem uma das resultantes, cujos efeitos prejudiciais podem ser sentidos, por exemplo, na interrupção de carreiras promissoras ou mesmo de um projeto profissional mais consistente.

Em outros termos, experiências laborais trans iluminam notadamente que a incorporação no mundo do trabalho não suprime desigualdades e subordinação social de gênero. Isto sugere problematizar que o direito ao trabalho de pessoas trans não se esgota nos limites de processos de inserção no mercado de trabalho, ao tempo que permite pensar que algum nível de hostilidade em torno de hierarquias e discriminações de gênero nas relações e práticas de trabalho (expressivas nas experiências laborais de pessoas trans) faz-se tolerado e/ou promovido no cotidiano das instituições. Isto ocorre porque também parte de mecanismos sofisticados de acirramento da competição, do controle, da coerção, bem como da sujeição e da divisão dos/as trabalhadores/as. Tais práticas tendem ao tolerado e/ou promovido, porque também apontam para o que é funcional à intensificação do processo de exploração-dominação, não apenas do segmento de trabalhadores/as trans, mas de toda a classe trabalhadora.

Chamam à atenção muitas destas práticas de preconceito/discriminação estarem generalizadas entre agentes dos âmbitos laborais (setores privado e público), dentre os/as quais, superiores hierárquicos/as, colegas de trabalho, 
usuários/as ou destinatários/as dos serviços prestados. Tal cenário pode constituir, em alguns casos, assédio moral ${ }^{2}$ como também expressão de violência transfóbica no trabalho. É sabido que resultantes do assédio moral comportam repercussões nocivas aos/às trabalhadores/as, como efeitos deletérios à saúde física e/ou mental, desligamentos e afastamentos dos postos de trabalho indesejados, transferências do trabalho ou mudanças na função (a pedido ou não).

O serviço público, por exemplo, consistiu historicamente numa casamata - nos termos de Almeida et al. (2014) - construída por pessoas trans como forma de acesso ao trabalho, visto o processo de admissão via concurso público representar uma vantagem na medida em que não há a necessidade tão clara de expor ao/à empregador/a a "aparência", além de o serviço público permitir maior proteção ao processo de afirmação do gênero identificado, especialmente quando no início de modificações corporais e/ou ainda não lograda a retificação de nome e sexo na documentação, no entanto, não significa necessariamente condições favoráveis à permanência no mesmo (ALMEIDA et al., 2014).

Esta casamata está mais frágil, todavia, no contexto atual. Em primeiro lugar, porque nas últimas décadas nos diferentes níveis governamentais (municipal, estadual e federal) se intensificaram as práticas de contratação de servidores/as públicos/as sem concurso público, seja através da progressiva terceirização de atividades, seja pela entrega de setores inteiros da execução de políticas sociais, por exemplo, às Organizações Sociais e às fundações, entre outras formas de introdução de interesses de mercado no setor público. Além disso, são crescentes as retiradas de direitos dos/as trabalhadores/as do setor público, como direitos previdenciários, direito à progressão funcional e de ameaças de retirada de direitos, inclusive à estabilidade no exercício da função, como intencionam vários projetos de "reforma administrativa" apresentados por parlamentares no presente cenário.

Vale destacar que sob o argumento da crise fiscal, o setor público (sobretudo o federal), tem reduzido os concursos públicos para recomposição de quadros civis na administração pública e investido tanto na contratação de militares (Marinha, Exército e Aeronáutica), quanto nas polícias. Desta forma, a menos que as pessoas trans estejam em altos cargos do Poder Executivo, Legis-

${ }^{2} \mathrm{O}$ conceito de assédio moral é polissêmico, mas, a despeito da variação segundo o país ou o/a autor/a, há convergências de que relacionado a condutas, comportamentos e práticas abusivas e violentas - expressos de diferentes formas no ambiente de trabalho -, de caráter repetitivo, sistemático e prolongado. Assim, configura-se pelo caráter processual, de modo que situações esporádicas ou isoladas de constrangimentos, hostilidades e discriminações são atos de violência, mas não constituem propriamente assédio. 
lativo, Judiciário ou nas Forças Armadas ou policiais, sua segurança e condições de trabalho também se encontram ameaçadas, inclusive no setor público. Além disso, mesmo em contextos anteriores mais favoráveis aos direitos dos/as servidores/as públicos/as, as pessoas trans não estavam imunes aos assédios.

Importa ressaltar que o assédio moral assume algumas especificidades nos setores públicos e privados:

No privado é mais evidente, dura menos tempo e termina em geral com a saída da vítima. No setor público, o assédio moral pode durar anos, pois, em princípio, as pessoas são protegidas e não podem ser demitidas, a não ser devido a uma falta muito grave. Por esta razão, os métodos de assédio são, neste caso, mais perniciosos e produzem resultados dramáticos sobre a saúde, bem como sobre a personalidade das vítimas (HIRIGOYEN, 2015, p. 124).

$\mathrm{Na}$ seara pública, embora a chance de demissão/exoneração do/a trabalhador/a trans ainda hoje se configure consideravelmente menor do que na iniciativa privada, a condição de estabilidade é igualmente compartilhada com aqueles/as que protagonizam violências transfóbicas. Situações de assédio moral direcionadas a funcionários/as trans os/as submetem, portanto, a condições desiguais e expressivamente desvantajosas à aprovação nos estágios probatórios, à permanência duradoura num mesmo setor e posto de trabalho ou até mesmo à manutenção no emprego.

Dificuldades de inserção de pessoas trans no mercado de trabalho também podem abranger a percepção, sob o ponto de vista do/a empregador/a, de ser mais custoso contratar um/a trabalhador/a trans. Isto ocorreria, porque tal contratação exigiria investimento no cultivo de posturas e práticas não discriminatórias nas rotinas e relações de trabalho (as quais são indissociáveis das relações e práticas de gênero), como por exemplo: proteção para que não haja exposição da documentação civil do/a trabalhador/a quando ainda não estiver retificada, disponibilidade de banheiros e uniformes em conformidade com a identidade de gênero expressa pelo/a próprio/a trabalhador/a, repreensão a condutas não respeitosas da identidade de gênero no seio das relações interpessoais no trabalho, entre outras. Associado à percepção de que a contratação de pessoas trans seria mais custosa existe, também, por parte de alguns/algumas empregadores/as o receio de judicialização devido às situações de preconceito/discriminação que possivelmente serão vivenciadas pelos/as trabalhadores/as trans no âmbito laboral. Nesta esteira, a contratação de pessoas trans pode ser acompanhada da premissa de que é potencialmente geradora de 
conflitos e constrangimentos nas relações interpessoais e institucionais nos ambientes laborativos em que se inserem.

Por outro lado, também observamos a presença de narrativas de que a busca, algumas vezes desesperada de contratação e permanência nos espaços e postos de trabalho, podem produzir efeitos de maior envolvimento, objetivo e subjetivo, de trabalhadoras/es trans com repercussões na intensificação de sua subordinação, no engajamento e produtividade no trabalho, como forma de "retribuição" à contratação, e como meio de reconhecimento pessoal e do valor (no sentido simbólico e não econômico) do seu trabalho, como parte da seara de preconceitos e discriminações que circunscrevem suas trajetórias laborais e de vida.

Também, pessoas trans podem engajar-se mais intensamente no trabalho e no desempenho das funções laborativas quando encontram respeito/reconhecimento da identidade de gênero num determinado ambiente laboral, o que guarda relação com o receio de este configurar um cotidiano que não pode ser logrado numa outra realidade institucional. Como afirma Souza-Lobo (1991, p. 166), ao refletir sobre o trabalho no feminino, "as condições ótimas de produtividade são socialmente recriadas através da hierarquia de gêneros [...]".

$\mathrm{Na}$ seara do pertencimento de classe, organicamente articulado ao pertencimento de gênero, pode-se refletir que condições e relações laborais mais ou menos favoráveis, na particularidade do segmento de trabalhadores/as trans, são ainda, em grande proporção, mediadas pelo acesso à construção corporal no gênero afirmado e à retificação de nome e sexo na documentação civil. Esta é uma problemática que corrobora e põe em evidência outras dimensões e a complexidade da divisão sexual do trabalho e das exigências do mercado de trabalho.

Numa ordem social cis-heteronormativa e patriarcal, a passabilidade ${ }^{3}$ favorece a preservação e o drible de constrangimentos, humilhações, violações

3 Passabilidade diz respeito a não ser identificado(a)/reconhecido(a) no convívio social como trans, ou seja, a pessoa trans é socialmente lida como pessoa cisgênera. Nas palavras de Vergueiro (2015, p. 213-214), a invisibilidade - ou passabilidade cis - envolve dimensões visuais e estéticas (formas corporais, vestimentas, expressões 'generificadas', às quais se atribuem gêneros), sonoras (tom, timbre, vocabulário) ou institucionais (documentação, acesso a recursos, dentre outros). Não significa, importante ressaltar, que toda pessoa trans deseja, ou possui condições sociais e econômicas de realizar, modificações corporais, ou que toda pessoa trans almeja a "passabilidade cis". Igualmente importante ressaltar que pessoas trans "passáveis" podem optar por assumir publicamente sua identidade trans, ou optar por publicizá-la em determinadas esferas, ou momentos, de sociabilidade, enquanto noutras e noutros não, por diferentes motivações em ambos os casos. 
de direitos e violências outras, em distintas e variadas interações cotidianas e dimensões da vida social, dirigidas aos corpos trans. Neste sentido, a passabilidade pode permitir condições mais favoráveis de inserção/manutenção no mundo do trabalho informal e formal mas, especialmente neste último (quando não há acesso à retificação do registro civil), essa condição pode ser inviabilizada em razão da suposta discordância entre corporalidade/identidade de gênero e a documentação apresentada. É válido registrar que uma pessoa trans pode não retificar o registro civil por motivos subjetivos, mas também pode não fazê-lo em razão da classe social a que pertencem, pois os segmentos mais pobres da classe trabalhadora muitas vezes não dispõem de acesso suficiente à informação (que permita, por exemplo, ir ao cartório efetivar o procedimento), não dispõem de documentos civis e mesmo de recursos mínimos como dinheiro para o transporte público até o cartório. Além disso, alguns/algumas dependem economicamente de suas famílias de origem (para residirem e/ou se alimentarem) e estas famílias se opõem à alteração dos documentos.

Estreitamente relacionada às dificuldades de ingresso/permanência de trabalhadores/as trans no trabalho formal, a inserção na informalidade do mercado de trabalho - que, em princípio, prescinde de publicização da documentação de identificação civil - pode constituir uma via acionada pelas pessoas trans com vistas a assegurar a reprodução social. Isto ocorre porque ela pode conter a possibilidade de um cotidiano laboral de maior conforto e segurança, no que envolve o respeito à identidade/expressão de gênero, permitindo o uso de estratégias de obtenção/manutenção da passabilidade, ou seja, de não revelação da identidade trans, sobretudo, quando não foi obtido pelo/a trabalhador/a o reconhecimento jurídico da sua identidade de gênero. ${ }^{4}$

A despeito dos discursos contemporâneos que valorizam o empreendedorismo e a autonomia do/a trabalhador/a, vemos que informalidade não é um caminho fácil. Ela também significa dimensões variadas de instabilidade profissional, precarização laboral e desproteção social e trabalhista. O que muitas ve-

4 Importa sublinhar que, sobretudo no bojo da reestruturação capitalista, trabalhadores/as informais não compõem um bloco homogêneo, pois a informalidade caracteriza-se pela heterogeneidade de situações de trabalho. Nas duas categorias predominantes do Processo de Informalidade: trabalho assalariado sem registro e trabalho por conta própria, há distintos e diversificados modos de inserção (CACCIAMALI, 2000). A última, por exemplo, incorpora proprietários/as de negócios na produção ou na prestação de serviços, trabalhadores/as de rua (como camelôs, vendedores/as ambulantes etc.), dentre outras formas de trabalho informal, as quais contemplam ocupações exercidas em domicílio, local público etc. (CACCIAMALI, 2000). Isto implica, com efeito, uma gama também diferenciada de condições e relações laborais, devido às diferentes posições que trabalhadores/as ocupam na informalidade. 
zes ocorre é a imposição de um dilema: a obtenção do direito ao emprego assalariado formalmente contratado pode implicar a subtração de outro direito, o direito ao reconhecimento/respeito da identidade de gênero. Nestes termos, onde ambos os caminhos comportam perdas, não é eventual a "escolha" do caminho da informalidade.

No contexto da nova dinâmica ofensiva do capital, trabalhadores/as são cada vez mais responsabilizados/as a dotar-se de "empregabilidade", donde, no elenco de atributos para manter-se empregável/empregado(a), difundese que adquirir qualificação (educação e formação profissional) é a única alternativa possível para escapar da inserção em ocupações precárias e no desemprego. Mecanismo que escamoteia o problema da precarização social no mundo do trabalho e transforma a qualificação no fetiche capaz de romper este processo (ANTUNES, 1999; SEGNINI, 2000). A trajetória das pessoas trans muitas vezes é uma eficiente ilustração deste fetiche, pois o flagelo do desemprego direto, os distintos modos de precarização, a informalização do trabalho e a remuneração instável e/ou depauperada compõem, de modo expressivo, as trajetórias laborais de pessoas trans, a despeito de muitas destas pessoas disporem da escolaridade/qualificação profissional exigidas pelo mercado.

Assim, o desemprego crescente de trabalhadores/as de maior escolaridade, qualificação e profissionais com experiências em níveis hierárquicos superiores (SEGNINI, 2000) permite "relativizar essa perspectiva instrumental da educação, que se expressa como se fosse capaz de garantir o emprego e a ascensão na hierarquia das empresas e na escala salarial, ou seja, como sendo capaz de garantir empregabilidade" (SEGNINI, 2000, p. 25).

A desigualdade de rendimentos, direitos e condições de trabalho entre homens e mulheres, brancos/as e negros/as, com o mesmo tempo de escolaridade, também expressa, de acordo com Segnini (2000), o fetiche da qualificação (educação e formação profissional). Neste sentido:

[...] a qualificação para o trabalho é uma relação social, muito além da escolaridade ou da formação profissional. Trata-se de uma relação social (de classe, de gênero, de etnia, geracional), que se estabelece nos processos produtivos, no interior de uma sociedade regida pelo valor de troca e fortemente marcada por valores culturais que possibilitam a construção de preconceitos e desigualdades (SEGNINI, 2000, p. 39).

Daí, pode-se afirmar que não há uma necessária correspondência entre trajetórias de escolarização e trajetórias laborais trans, se as vemos à luz da rela- 
ção educação e trabalho como necessariamente mediatizada pelas relações de gênero. Tal mediação situa corpos trans na estrutura ocupacional e de rendimentos, e na divisão social e sexual do trabalho, de forma expressivamente precarizada, a despeito de disporem de escolaridade/formação profissional. É nesta direção que assimetrias e desigualdades de gênero experienciadas pelas pessoas trans, (re) produzidas e apropriadas no interior do mundo do trabalho, podem desqualificar ou invisibilizar a sua qualificação para o exercício do trabalho.

Além disso, pode-se aventar que as formas como se estabelecem seus pertencimentos de gênero ocorrem de maneiras distintas da população cisgênera. Assim, na população cisgênera vemos que os processos de inserção em redes de aprendizado de ofícios e/ou de ingresso em vagas de trabalho se dá pari passu com os processos pelos quais as pessoas são admitidas no "mundo dos homens" ou no "mundo das mulheres", muitas vezes ainda na infância ou adolescência. No caso das pessoas trans, ainda que elas ocorram na infância/adolescência com base na identidade civil, estas inserções ocorrem de forma disruptiva, marcada por vezes pelas vivências de inadequação às exigências ocupacionais que assumem formas generificadas com base nas concepções hegemônicas de feminilidade ou masculinidade. ${ }^{5}$

Trajetórias laborais de trabalhadores/as trans conformam-se entrelaçadas por dificuldades: de conseguir trabalho (mesmo que precário, sob exígua ou nenhuma proteção social); de vivenciar relações laborais não degradantes; de obterem estabilidade de emprego; de assegurarem renda ou estabilidade da renda, entre outras. Há, portanto, uma distribuição desigual da instabilidade, da incerteza e da degradação na esfera da produção social, porque a precarização do e no trabalho, e sua expressão mais aguda, o desemprego, também comporta uma divisão sexual. Neste sentido, experiências laborais trans conformam-se sob a ingerência da divisão sexual do trabalho, a qual incorpora o segmento de trabalhadores/as trans de modo desigual e diferenciado.

5 Assim, uma mulher trans dos segmentos mais pobres da classe trabalhadora foi, muitas vezes, um "menino" ou adolescente que não conseguiu atender às exigências educacionais e laborais atribuídas hegemonicamente ao masculino naquela fração de classe (força física, liderança, habilidade e gosto por máquinas, entre outras). Da mesma forma, um homem trans destes mesmos segmentos foi, muitas vezes, uma "menina" ou adolescente que não conseguiu se ajustar a habilidades presumidas nas mulheres pobres (habilidade culinária, expertise em limpeza de ambientes e coisas, capacidade de cuidado especialmente de crianças, apreço por ocupações estéticas: cabeleireira, manicure, esteticista, entre outras). Quando conseguem mais tarde terem suas identidades reconhecidas, nem sempre receberam o treinamento necessário nem construíram redes de relacionamento profissional (network) para se inserirem em ocupações mais interessantes para si. 
Corpos, gêneros e sexualidades inteligíveis - cuja referência reside nas relações e práticas de gênero cisheteronormativas-patriarcais -, configuram-se enquanto exigência da divisão social e sexual do trabalho (ainda que não institucionalizada e, às vezes, exercida com discrição e por mecanismos quase imperceptíveis). Esta dinâmica opera na distribuição desigual de trabalhadores/as, pois designa os/as mais ou menos empregáveis, bem como a alocação mais ou menos precária, na esfera da produção social.

O trabalho na expressão trans é acompanhado de múltiplas formas de hierarquia, subordinação e discriminação de gênero, relativas à inserção e à permanência no mundo do trabalho. Ele evidencia que negociações da força de trabalho e das condições de sua exploração-dominação envolvem negociações face com as normas e mecanismos regulatórios da ordem de gênero (bináriabiologicista), expressas e tecidas nas relações e interações sociais no âmbito da divisão sexuada do trabalho e do mercado.

Experiências laborais trans corroboram para tornar visível que relações de gênero (relações desiguais, antagônicas e de poder), necessariamente, conformam e estruturam o mundo do trabalho. Contribuem, portanto, para questionar relações e práticas de trabalho supostamente assexuadas ou "neutras", paradigmas, como alerta Hirata (2002, 2016), "gender-blinded" persistentes predominantes no âmbito da sociologia do trabalho, a despeito de recusas, renovações e avanços provocados pelas contribuições feministas em torno da divisão sexual do trabalho. Limites e lacunas adensados quando se pensa que relações invisíveis entre diversidade de gênero e trabalho prevalecem dominantes em pesquisas e análises da produção sociológica a respeito da classe trabalhadora e do mundo do trabalho em geral, bem como da divisão sexual do trabalho em particular.

Experiências laborais trans reiteram que a divisão do trabalho e do mercado de trabalho também é sexual. Trata-se de condições e relações laborais afetadas pela própria existência e dinâmica da divisão sexual do trabalho. Tratase, em dialética articulação, de condições e relações laborais que contribuem para elucidar a complexidade e outras dimensões da dinâmica da divisão sexual do trabalho, à medida que possíveis de serem visualizadas a partir da condição trans (BRITO, 2019).

Esses são processos que impulsionam a refletir acerca da importância de incorporar ao conceito e debate contemporâneo da divisão sexual do trabalho a problemática da diversidade de gênero, perspectiva que, a nosso ver, permite enriquecer análises e pesquisas na área. 


\section{Problemática da divisão sexual do trabalho e da diver- sidade de gênero em reflexão}

A indissociabilidade entre relações de classe e relações de gênero constitui um aspecto essencial da problemática da divisão sexual do trabalho. Estudos feministas em torno desta problemática intentam mesmo "não pensar isoladamente, não imperializar uma relação social, mas, ao contrário, esforçar-se para pensar conjuntamente em termos de complexidade e de co-extensividade as relações sociais fundamentais: de classe e de sexo" (KERGOAT, 1989, p. 93). ${ }^{6}$

Tal esforço teórico-metodológico implica a recusa de hierarquizar uma ou outra relação social, relações de classe ou relações de sexo, pois não há contradições principais e contradições secundárias: "uma relação social não pode ser um pouco mais viva do que uma outra; ela é ou não é” (KERGOAT, 1986, p. 83).

Nesta direção, Hirata e Kergoat (1994, p. 95-96) afirmam a impossibilidade de segmentar as relações e práticas sociais, situando de um lado a relação de interesses antagônicos entre homens e mulheres, e de outro, a relação de interesses antagônicos entre capital e trabalho. Nas palavras das autoras, relações sociais de classe e relações sociais de sexo se superpõem e, portanto, relações de classe são sexuadas e relações de sexo são classistas.

A divisão sexual do trabalho constitui objeto de trabalhos precursores em diversos países, no entanto, na França, sob o impulso do movimento feminista, surgem no início da década de 1970 inúmeros trabalhos que gerariam as bases teóricas desse conceito (HIRATA, KERGOAT, 2007; KERGOAT, 2009) preocupados, sobretudo, com as dimensões de classe e gênero ${ }^{7}$, como já explicitado. Inicialmente, as análises debruçam-se na (e denunciam a) massa de atividades realizadas gratuitamente pelas mulheres na esfera doméstica, ou seja, o que se conviria chamar "trabalho", mas posteriormente abordam também as

${ }^{6} \mathrm{Na}$ literatura feminista francesa verifica-se o amplo uso da categoria relações sociais de sexo. $\mathrm{O}$ artigo não se direciona a enfocar fundamentos teóricos e políticos da utilização da categoria relações sociais de sexo ou da categoria relações de gênero. Ressalta-se a imprescindibilidade dos estudos feministas aqui apropriados porquanto, a partir da perspectiva de totalidade, elucidam a indissociabilidade entre relações de classe e relações de gênero/relações sociais de sexo.

7 Ao contrário dos estudos de feministas negras estadunidenses que destacarão a dimensão racial em análises das relações sociais e de gênero na dinâmica capitalista colonial e pós-colonial. 
atividades por elas realizadas na esfera profissional (HIRATA; KERGOAT, 2007; KERGOAT, 2009).

A estruturação moderna da divisão sexual do trabalho - qual seja, trabalho assalariado/doméstico, fábrica-escritório/família - configura-se indissociável ao florescimento do capitalismo (KERGOAT, 1989, 2002), portanto, "a noção de 'trabalho doméstico' não é nem a-histórica nem trans-histórica” (KERGOAT, 1989, p. 95), trata-se de uma forma historicamente determinada de trabalho reprodutivo, inseparável da sociedade salarial (KERGOAT, 1989, 2002, 2009).

A divisão sexual do trabalho - que consiste na "forma de divisão do trabalho social decorrente das relações sociais entre os sexos" (KERGOAT, 2009, p. 67) - possui como características inerentes a designação prioritária das mulheres à esfera reprodutiva e dos homens à esfera produtiva, bem como a ocupação dos últimos em funções com maior valor social adicionado (políticas, religiosas, militares etc.) (KERGOAT, 2009). Esta forma de divisão social do trabalho encontra-se em todas as sociedades, cujas modalidades concretas (concepção de trabalho reprodutivo, lugar das mulheres no trabalho mercantil etc.) variam fortemente (HIRATA; KERGOAT, 2007; KERGOAT, 2009). Não configura, portanto, dado imutável, assume formas históricas e conjunturais, pois está sujeita a mutações, deslocamentos, novas fronteiras e configurações, haja vista constituir-se mesmo como construção social e histórica (KERGOAT, 1989, 2009; SOUZA-LOBO, 1991; HIRATA; KERGOAT, 2007).

No entanto, a divisão sexual do trabalho possui princípios organizadores que se mantêm a despeito de suas variações no tempo e espaço: os princípios da separação e da hierarquia, ou seja, a distinção entre trabalhos de homens e de mulheres e a maior valorização do trabalho masculino em detrimento do feminino (KERGOAT, 2009) - "valor" no sentido antropológico e ético e não econômico, pois "produção 'vale' mais do que reprodução, produção masculina 'vale' mais do que produção feminina (mesmo quando uma e outra são idênticas)” (HIRATA; KERGOAT, 2003, p. 113).

No domínio da sociologia, há duas grandes teorias acerca da divisão sexual do trabalho que se figuram opostas e divergentes (HIRATA, 2002, p. 279). De um lado, a concepção de complementariedade entre homens e mulheres e conciliação de papéis, na qual "[...] os status sociais entre os sexos são presumidamente iguais (HIRATA; KERGOAT, 2003, p. 111 - grifo no original), daí a divisão sexual do trabalho pensada "em termos de 'vínculo social', por meio de seus conteúdos conceituais (solidariedade orgânica, complementariedade, conciliação, coordenação, parceria, especialização e divisão dos papéis)" (HIRATA, 
2002, p. 279). A segunda teoria acerca da divisão do trabalho entre os sexos remete "a uma conceitualização em termos de 'relação social' (divisão do trabalho, contradição, antagonismo, oposição, dominação, opressão, poder) e a uma teoria geral das relações sociais" (HIRATA, 2002, p. 279).

Este último referencial teórico - que os estudos feministas reivindicam - conceitua, portanto, divisão sexual do trabalho e relações sociais de sexo/gênero como expressões indissociáveis e, antes de tudo, relações desiguais, hierarquizadas, antagônicas e de poder (KERGOAT, 2009). Nesta perspectiva, a divisão sexual do trabalho tem o status de enjeu - isto é, "o que está em jogo, em disputa, o desafio" - das relações sociais de sexo (KERGOAT, 2009, p. 71).

Pensar a divisão sexual do trabalho em termos de relação social permite desvelá-la como operante não apenas no que diz respeito às mulheres, ao trabalho doméstico, à esfera do privado ou à da reprodução (KERGOAT, 1989, 2002). Ela suscita questionar e redefinir o conceito de "trabalho", no sentido de afastá-lo do âmbito exclusivo das relações mercantis e de recusar "disjunções clássicas entre trabalho/não-trabalho, trabalho assalariado/trabalho doméstico", de modo a restabelecer "vínculos entre o que até então havia sido separado" (KERGOAT, 2002, p. 235). Destarte, a divisão sexual do trabalho "trata-se de uma problemática (e não da abertura de um novo campo regional) que atravessa e dá sentido ao conjunto das relações sociais que a expressão 'divisão social do trabalho' abrange" (KERGOAT, 2002, p. 235).

Deste modo, estudos feministas em torno da problemática da divisão sexual do trabalho questionam o conceito de trabalho e formulam uma definição mais ampla, a qual abrange o trabalho assalariado e doméstico, formal e informal, remunerado e não-remunerado (KERGOAT, 1989, 2002, HIRATA, 2002). A partir de então, o trabalho doméstico, bem como as particularidades do trabalho assalariado das mulheres, "não são mais 'exceções' a um modelo supostamente geral: essa problemática supõe uma tentativa de refazer um modelo geral do qual essas mesmas especificidades seriam elementos constitutivos" (KERGOAT, 2002, p. 235 - grifos no original). ${ }^{8}$

Tal esteira de reflexão permite compreender que experiências laborais trans e suas particularidades não são "exceções" das relações e práticas de trabalho supostamente "gerais" ou "neutras", mas são expressão e parte constitu-

${ }^{8}$ Cabe apontar que a perspectiva das feministas francesas sobre a divisão sexual do trabalho põe em marcha uma reflexão que não alcança a problemática do trabalho forçado, escravo e/ou "livre" nos regimes pós-abolição protagonizados por homens e mulheres negros/as. Tais experiências adicionam complexidades às clássicas divisões esfera pública/doméstica, produção/reprodução. Questão que está por ser aprofundada em trabalhos futuros. 
tiva da dimensão sexual da divisão do trabalho, do mercado de trabalho, de ocupações generificadas e tarefas atinentes ao processo de trabalho. Também por esta razão, sublinha-se as potencialidades das experiências laborais trans para iluminar as análises mais amplas acerca do processo de radicalização da precarização social no mundo do trabalho e, em especial, do conceito e debate contemporâneo da divisão sexual do trabalho.

Nas palavras de Souza-Lobo (1991, p. 146), a ideia de que a divisão sexual do trabalho não somente separa e articula produção e reprodução, mas estrutura as relações no âmbito do trabalho produtivo, "permite recolocar a questão da relação entre a dinâmica das relações capitalistas de trabalho e a força de trabalho feminina sob um ângulo que integra os dois níveis, sexualizando as relações de trabalho e as relações sociais".

Pesquisas e análises feministas acerca da divisão sexual do trabalho questionam e se contrapõem, portanto, à escamoteação da dimensão sexual da divisão social do trabalho e do mercado de trabalho predominante nas análises do mundo do trabalho, e evidenciam a imprescindibilidade de pensar a classe trabalhadora no feminino, pois:

É um fato marcante que essas análises referem-se a uma classe de sexo unívoca: a dos homens [...]. Se me permitem uma imagem, diria que os conceitos masculinos tiveram o papel de um retrovisor: o cenário sendo apreendido apenas por intermédio desse retrovisor, as mulheres operárias permaneceram, de algum modo, no ponto morto do carro sociológico; elas não são visíveis (KERGOAT, 1986, p. 80-81).

Notabilizar "o sexo do trabalho", ou que "a classe operária tem dois sexos” (SOUZA-LOBO, 1991), não significa apenas questionar a utilização corrente do masculino em análises que, não raramente, referem-se a contextos envolvendo trabalhadoras. Implica, pois, a recusa a categorias e paradigmas sexualmente cegos predominantes nas ciências sociais e na literatura que trata a classe trabalhadora e o mundo do trabalho (SOUZA-LOBO, 1991; HIRATA; KERGOAT, 1994), visto que o gênero enseja condições assimétricas e desiguais no processo de exploração-dominação de classe, na esfera imediata do trabalho e da produção e fora dela. Trata-se, portanto, de desvelar que:

[...] as práticas, a consciência, as representações, as condições de trabalho e de desemprego dos trabalhadores e das trabalhadoras são quase sempre assi-

9 Cf. nota 1 deste capítulo. 
métricas e que raciocinar em termos de unidade da classe operária sem considerar o sexo social leva a um conhecimento truncado - ou pior falso - do que é uma classe social (HIRATA; KERGOAT, 1994, p. 95).

Desconsiderar o sexo social na expressão das identidades trans, categorias que compõem e ampliam a heterogeneidade de gênero e de classe, configura processos que contribuem para falsear a compreensão de classe social e também do gênero. Evidenciar, na perspectiva da diversidade de gênero, sexo social e classe social como categorias indissociáveis constitui aporte fundamental para questionar a concepção da classe trabalhadora como massa homogênea e o caráter assexuado das relações e práticas de trabalho.

Pesquisas sobre a divisão sexual do trabalho evidenciam que dominação e subordinação de gênero produzem-se e reproduzem-se nas distintas esferas da vida social (SOUZA-LOBO, 1991, p. 152), de modo que "as condições de negociações da força de trabalho não são as mesmas, o que nos permite concluir pela sexualização da força de trabalho e, consequentemente, das relações e práticas de trabalho" (SOUZA-LOBO, 1991, p. 152).

Daí porque, na assertiva de Souza-Lobo (1991, p. 159), a maior ou menor participação no mercado de trabalho não elimina a subordinação social das mulheres, evidenciada nas próprias relações de trabalho, nos baixos salários e na persistência da segregação ocupacional. A divisão sexual do trabalho "produz e reproduz a assimetria entre práticas femininas e masculinas, constrói e reconstrói mecanismos de sujeição e disciplinamento das mulheres, produz e reproduz a subordinação de gênero dominação" (SOUZA-LOBO, 1991, p. 171).

A passagem de categorias neutras a categorias sexuadas e o questionamento que essa passagem suscita às teorias e aos conceitos existentes nas ciências sociais parecem constituir a contribuição mais importante das pesquisas em torno da problemática da divisão sexual do trabalho (HIRATA, 2002, p. 275). Também a respeito da contribuição desta problemática às ciências sociais, Souza-Lobo (1991, p. 151) evidencia que:

O aporte mais importante que as pesquisas sobre a divisão sexual do trabalho trouxeram para as ciências sociais terá sido talvez o de apontar para a necessidade de uma metodologia que articule relações de trabalho e relações sociais, práticas de trabalho e práticas sociais.

Mais do que acrescentar sufixos femininos, o aporte teórico-metodológico de pesquisas sobre a divisão sexual do trabalho propõe-se a desvelar a 
complexidade da divisão social do trabalho, notadamente, que "O trabalho também tem sexo” (SOUZA-LOBO, 1986, s/p). A partir da mediação entre relações de gênero e relações de classe, evidencia-se a imprescindibilidade de "desomogeneizar" a classe trabalhadora e de apreender assimetrias e desigualdades nas condições e relações de trabalho que, necessariamente, circunscrevem o trabalho feminino e masculino. Tal aporte teórico-metodológico produz, portanto, avanços na teoria crítica ao notabilizar o vínculo orgânico entre relações e práticas de trabalho e relações e práticas de gênero e, antes de tudo, relações e práticas de gênero enquanto estruturais e constitutivas da totalidade das relações e práticas sociais.

A gênese do conceito de divisão sexual trabalho dá-se em torno de concepções rígidas de masculinidades e feminilidades, de modo que a diversidade trans não constitui objeto ocupado no interior da problemática de gênero e relações de gênero em estudos feministas pioneiros acerca da divisão sexual do trabalho. Nesse sentido, os estudos da divisão sexual do trabalho, em que pese sua contribuição para o entendimento de que sexo/gênero importam na organização do trabalho na sociedade capitalista, assumem uma unidade nos polos masculino/homem e feminino/mulher que desconsidera os processos sóciohistóricos e culturais transversais a essas definições. Supõe-se que todas as mulheres possuiriam posições semelhantes nas relações sociais.

Isto é relevante quando se analisa, por exemplo, relações de poder em torno de trabalhadores/as negros/as que, mesmo posicionados/as no segmento cisheteronormativo, apresentam conformações variadas e subalternizadas de feminilidade e masculinidade ${ }^{10}$ na dinâmica social e no trabalho.

Do ponto de vista da diversidade de gênero, tais concepções rígidas conformam-se histórica e socialmente estreitas à matriz do binarismo das relações de gênero, na qual o corpo/sexo constitui referência ao pertencimento de gênero (feminino ou masculino) e ao direcionamento do desejo sexual, especificamente dirigido ao sexo/gênero oposto, visto que "a instituição de uma heterossexualidade compulsória e naturalizada exige e regula o gênero como uma relação binária em que o termo masculino diferencia-se do termo feminino, realizando-se essa diferenciação por meio das práticas do desejo heterossexual"

\footnotetext{
${ }^{10}$ Vale lembrar os estudos de Bell Hooks que lançam o questionamento se as mulheres negras podem ser consideradas mulheres. Tomando como referência o discurso revolucionário de Soujourner Truth nos EUA em fins do século XIX, Hooks problematiza as relações de dominação-exploração a que foram e são submetidas as mulheres negras ao longo dos processos sócio-históricos coloniais e que rebate sobre sua própria condição de gênero (HOOKS, 2019).
} 
(BUTLER, 2003, p. 45). Matriz de gênero que, portanto, produz e reproduz a heterossexualidade compulsória e a oposição binária homem-mulher fundada em diferenças biológicas (supostamente a-históricas e pré-discursivas) (BUTLER, 2003; LOURO, 2004).

Trata-se de uma forma historicamente determinada de concepção de corpo, gênero e sexualidade, que, ao sabor de uma multiplicidade de processos de ordem econômica, política, cultural e social, passa a constituir-se na sociedade ocidental a partir do século XVIII, como demonstra estudos do historiador Thomas Laqueur (2001), convergindo à perspectiva de que o sexo é uma invenção.

A categoria sexo, nesta perspectiva, é uma forma que supõe o corpo como "natural”, "dado", "evidente”, lhe atribuindo caráter imutável, a-histórico, pré-discursivo, em detrimento das relações sociais que, necessariamente, o circunscrevem, (re) constroem, (re) produzem. Não se trata aqui de negar a materialidade dos corpos, mas de questionar "a ideia de que corpo e sexo são instâncias estáveis e sólidas ao longo do tempo" (ALMEIDA, 2011, p. 18), “de valorizá-los e desvelá-los como produções narrativas dos sujeitos e da sociedade em determinadas situações" (ALMEIDA, 2011, p. 23). Trata-se, portanto, de "pensar que, assim como o gênero não é uma categoria dada ou fixa, também o sexo e o corpo precisam ser examinados como construções sociais e históricas" (ALMEIDA, 2011, p. 19).

Nesta matriz de gênero binária-biologicista-heteronormativa e também racista, a concepção de mulheres e homens "verdadeiras/os" repousa restrita a relações de coerência e continuidade nos contornos da sequência (supostamente) causal e estável entre sexo-gênero-sexualidade (BUTLER, 2003; LOURO, 2004); "daí porque aqueles que escapam ou atravessam esses limites ficam marcados como corpos - e sujeitos - ilegítimos, imorais ou patológicos" (LOURO, 2004, p. 82).

Estudos feministas dos primeiros tempos sobre a problemática da divisão sexual do trabalho não se direcionaram à diversidade de gênero, pois permitem a visibilidade das relações de gênero tomadas na perspectiva da época. O aporte teórico-metodológico do conceito de divisão sexual do trabalho ilumina a complexidade do direito ao trabalho de pessoas trans, na medida em que problematiza e desvela mesmo relações de classe e relações de gênero, relações e práticas de trabalho e relações e práticas de gênero, enquanto expressões indissociáveis, ao tempo em que experiências laborais trans notabilizam e trazem problemáticas que põem em evidência outras dimensões e a complexidade da divisão sexual do trabalho, processos que impulsionam a pensar a divisão sexual 
do trabalho em termos das experiências trans. Além de acionarem desigualdades e discriminações oriundas da condição sexo/gênero, trabalhadores/as trans evidenciam uma "precariedade" na própria constituição de gênero sendo-lhes atribuída uma condição de sujeitos incompletos e, de certo modo, inferiores.

Diante do exposto, concordamos com Biroli $(2018$, p. 23) em sua afirmação de que "a divisão sexual do trabalho é um lócus importante da produção de gênero", assim como evidenciou Lobo (1986) em seus estudos anteriormente mencionados. Ao verificar-se que a divisão sexual do trabalho não atinge igualmente todas as mulheres e todos os homens, é possível reconhecer que gênero/sexualidade, raça e classe são relevantes e precisam ser visualizadas na organização desigual do trabalho da sociedade capitalista contemporânea.

\section{Considerações finais}

Apesar do cenário notoriamente desfavorável à classe trabalhadora donde desconstrução de direitos sociais trabalhistas e erosão de direitos historicamente conquistados por grupos socialmente discriminados, a exemplo da população LGBT, constituem expressões -, não se deve desconsiderar a realidade social em seu movimento e em suas contradições. Reafirma-se, assim, a imprescindibilidade da visualização de demandas e urgências do segmento de trabalhadores/as trans no âmbito de construção de políticas públicas, em especial na perspectiva da intersetorialidade, de modo a reconhecer e assegurar o direito ao trabalho de pessoas trans.

Reflete-se, também, a importância da literatura que trata a problemática da divisão sexual do trabalho direcionar-se à diversidade de gênero, de modo a dialogar com o desvelar da absorção diferenciada e desigual do segmento de trabalhadores/as trans na divisão sexual do trabalho, na medida em que hierarquia, subordinação e desigualdade de gênero (re) produzidas no mundo do trabalho potencializam e intensificam práticas sociais de exploração-dominação do trabalho na expressão trans.

A incorporação da problemática da diversidade de gênero ao conceito e debate contemporâneo da divisão sexual do trabalho fornece, a nosso ver, potencialidades às pesquisas e análises na área, e está, em orgânica vinculação, com potencialidades a confrontarem radicalmente a ordem social cisheteronormativa, patriarcal, racista e capitalista vigente. 


\section{Referências}

ALMEIDA, C. C. L. de. Corpo e gênero: articulando um debate. Em Pauta: teoria social e realidade contemporânea. Rio de Janeiro, v.9, n. 28, p. 17-27, dez. 2011.

ALMEIDA, G. S. de.; PILAR, A.; GEBRATH, Z. As relações de trabalho como um aspecto da assistência à saúde de pessoas trans. In: COELHO, M. T. A. D.; SAMPAIO, L. L. P. (Org.). Transexualidades: um olhar multidisciplinar. Salvador; EDUFBA, 2014, p. 187 -199.

. Identidade de gênero com ênfase nas pessoas trans: particularidades e acesso à saúde, trabalho e educação. In: NOGUEIRA, L; HILÁRIO, E; PAZ, T. T; MARRO, K. (Org.). Hasteemos a bandeira colorida: diversidade sexual e de gênero no Brasil. São Paulo: Editora Expressão Popular, 2018, p. 159-185.

ANTUNES, R. O mundo precarizado do trabalho e seus significados. Cadernos de Psicologia Social do Trabalho. São Paulo, v.2, n.1, p. 55-72, dez.1999.

BAGAGLI, B. P. "Cisgênero" nos discursos feministas: uma palavra "tão defendida; tão atacada, tão pouco entendida”. Campinas, SP: UNICAMP/ IEL/Setor de publicações, 2015.

BIROLI, F. Gênero e desigualdades: limites da democracia no Brasil. São Paulo: Ed. Boitempo, 2018.

BRITO, C. G. S. de. Diversidade de gênero no trabalho: trajetórias de inserção e permanência de homens trans no mercado de trabalho. Orientadora: Carla Cristina Lima de Almeida. 2019. Dissertação (Mestrado em Serviço Social) Centro de Ciências Sociais, Universidade do Estado do Rio de Janeiro, Rio de Janeiro, 2019.

BUTLER, J. Problemas de gênero: feminismo e subversão da identidade. Rio de Janeiro: Civilização Brasileira, 2003.

CACCIAMALI, M. C. Globalização e processo de informalidade. Economia e Sociedade. Campinas, v.9, n. 1, p. 153-174, dez. 2000.

GONZÁLEZ, L. Racismo e sexismo na cultura brasileira. In: UCPA - União dos coletivos Pan-Africanistas (Org.). Lélia González: primavera para as rosas negras. Diáspora Africana: Editora Filhos da África, 2018. 
HIRATA, H. Nova divisão sexual do trabalho? Um olhar voltado para a empresa e a sociedade. São Paulo: Boitempo, 2002.

. Entrevista com Helena Hirata. Idéias, São Paulo, v. 7, n. 1, p. 295-

318, jan. / jul. 2016. Entrevista concedida a Bárbara Castro; Mariana Roncato.

.; KERGOAT, D. A classe operária tem dois sexos. Estudos Feministas. Florianópolis, v. 2, n. 3, p. 93-100, 1994.

;

. A divisão sexual do trabalho revisitada. In: MARUANI, Mar-

garet; HIRATA, H. (Org.). As novas fronteiras da desigualdade: homens e mulheres no mercado de trabalho. São Paulo: Editora SENAC, 2003, p. 111123.

; . HIRATA, H.; KERGOAT, D. Novas configurações da divisão sexual do trabalho. Cadernos de Pesquisa., São Paulo, v. 37, n. 132, p. 595-609, set./dez. 2007.

HIRIGOYEN, M-F. Mal-estar no trabalho: redefinindo o assédio moral. $8^{\text {a }}$. ed. Rio de Janeiro: Bertrand Brasil, 2015.

HOOKS, B. E eu não sou uma mulher? Mulheres negras e feminismo. Rio de Janeiro: Rosa dos Tempos, 2019.

KERGOAT, D. Em defesa de uma Sociologia das relações sociais: da análise crítica das categorias dominantes à elaboração de uma nova conceituação. In: KARTCHEVSKY-BULPORT, A. et. al. O sexo do trabalho. Rio de Janeiro: Editora Paz e Terra, 1986, p. 79-93.

. Da divisão do trabalho entre os sexos. In: HIRATA, H. (Org.). Divisão capitalista do trabalho. Tempo Social. São Paulo, v. 1, n.2, p. 88-96, $2^{\circ}$ sem.1989.

. Problemática da divisão sexual relacionada à divisão social, e problemas das relações sociais. In: HIRATA, H. Nova divisão sexual do trabalho? Um olhar voltado para empresa e a sociedade. São Paulo: Editora Boitempo, 2002, p. 234-235.

. Divisão Sexual do trabalho e relações sociais de sexo. In: HIRATA, H. et al. (Org.). Dicionário crítico do feminismo. São Paulo: Editora UNESP, 2009, p. 67-75.

LAQUEUR, T. Inventando o sexo: corpo e gênero dos gregos a Freud. Rio de Janeiro: Relume Dumará, 2001. 
LOURO, G. L. Marcas do corpo, marcas de poder. In: Um corpo estranho: ensaios sobre sexualidade e teoria queer. Belo Horizonte: Editora $\mathrm{Au}-$ têntica, 2004.

SEGNINI, L. Educação, trabalho e desenvolvimento: uma complexa relação. Trabalho \& Educação. Belo Horizonte, n. 6, p. 14-46, jan./jun. 2000.

SOUZA-LOBO, E. [Orelha do livro]. In: KARTCHEVSKY-BULPORT, A. et. al. O sexo do trabalho. Rio de Janeiro: Paz e Terra, 1986.

A classe operária tem dois sexos: trabalho, dominação e resistência. São Paulo: Brasiliense, 1991.

VERGUEIRO, V. Por inflexões decoloniais de corpos e identidades de gênero inconformes: uma análise autoetnográfica da cisgeneridade como normatividade. 2015. Dissertação (Mestrado em Cultura e Sociedade). Universidade Federal da Bahia, Instituto de Humanidades, Universidade Federal da Bahia, Salvador, 2015. 
